\title{
FATIGUE ASSESSMENT OF OLD RIVETED RAILWAY BRIDGES: LABORATORY TESTING OF A REAL BRIDGE
}

\author{
JOSÉ M. ADAM*, PEDRO A. CALDERÓN ${ }^{1}$, MANUEL BUITRAGO ${ }^{1}$, ELISA \\ BERTOLESI ${ }^{1}$, JUAN J. MORAGUES ${ }^{1}$, SALVADOR IVORRA², BENJAMÍN \\ TORRES $^{2}$
}

\author{
*11 ICITECH, Universitat Politècnica de València \\ Camino de Vera s/n, 46022, Valencia, Spain \\ E-mail: joadmar@upv.es (J.M. Adam*), pcaldero@upv.es (P.A. Calderón), \\ mabuimo1@upv.es (M. Buitrago), elber4@upv.es (E. Bertolesi), jmorague@upv.es (J.J. Moragues) \\ Web page: http://www.upv.es \\ ${ }^{2}$ Department of Civil Engineering, Universidad de Alicante \\ 03690, Alicante, Spain \\ Email: sivorra@ua.es (S. Ivorra), benjamin.torres@ua.es (B. Torres) \\ Web page: http://www.ua.es
}

Keywords: Historical Structure, Fatigue, Monitoring, Riveted steel structure, Bridges.

\begin{abstract}
The bridge over the Quisi Ravine in Alicante Province (Spain), built between 1913 and 1915, consists of six 22-22-42-42-22-22 $m$ long steel Pratt truss spans, the lateral spans being isostatic and the central spans continuous. All the joints between the steel elements are riveted. As the bridge has been carrying railway traffic for more than 100 years, its condition needed to be assessed before carrying out the necessary repairsreinforcement to extend its service life. One of the most interesting tasks on the bridge involved a study of its fatigue behaviour to estimate its remaining useful life. Only a few kilometres away there happened to be another bridge with identical geometry over the Ferrandet Ravine, which had recently been dismantled and taken out of service and had carried the same railway traffic as the one over the Quisi Ravine. Advantage was therefore taken of this unique opportunity to test one of its isostatic spans in order to extrapolate the results to the Quisi Bridge. These tests were carried out at the ICITECH laboratories at the Universitat Politècnica de València in two different scenarios: 1) one test on a $22 \mathrm{~m}$ span, and 2) another on one of its girders, in both of which simulated railway traffic cyclical loads were applied. The results allowed us to estimate the number of trains that could pass over the bridge and its remaining service life, and also to define a monitoring method to help in decision making in case of possible failures of its component parts. The study also included an analysis of the bridge's robustness in local failures of some of its elements, which led to a further bridge cyclical loading test with a deliberately damaged component. Even though other researchers had previously carried out fatigue tests on full-scale riveted bridge elements, the ICITECH study is unique in that it is the first time a full-scale bridge has been subjected to fatigue tests. This work was accompanied by advanced numerical modelling studies considering the fracture mechanics theory.
\end{abstract}




\section{INTRODUCTION}

Structural maintenance and conservation received a lot of attention from the press and the media after events such as the collapse of the IW-35 bridge over the Mississippi in 2007 in Minneapolis, or the more recent case of the Polcevera Viaduct in Genoa in 2018. Special attention has been given to the older infrastructures nearing the end of their service life in which the effect of long-term continuous loads can have serious effects due to accumulated damage in their structural elements and can lead to fatigue failures. This is similar to the wellknown case of the damage caused by bending of aircraft wings or the effect of waves on ships' hulls. The case studied in the present work was an example of a steel railway bridge with riveted joints that had suffered wear and tear from the continual passage of trains over many years, which could have compromised the structure's fatigue safety without ever having reached the material's yield stress. Some researchers have already studied this phenomenon in this type of structure, for example the outstanding work by Pipinato et al [1].

The present work on estimating fatigue and the remaining service life of a steel railway bridge was part of the renovation of the Alicante-Denia line belonging to the Valencia Railway Company (FGV). This line was built between 1912 and 1915 and, besides its value as transport, forms part of the civil engineering heritage of Alicante and the Valencia Community. The work was also included in the EU's Horizon 2020 social challenges and in the UN's Sustainable Development Objectives.

After this Introduction, the paper includes: a) a description of the bridge, b) the research

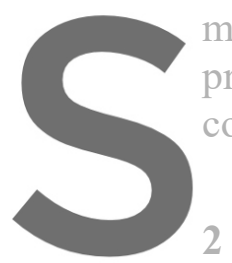
method followed, c preliminary, detailed ard conclusions drawn from th

\section{DESCRIPTION OF THIL BRIDGE}
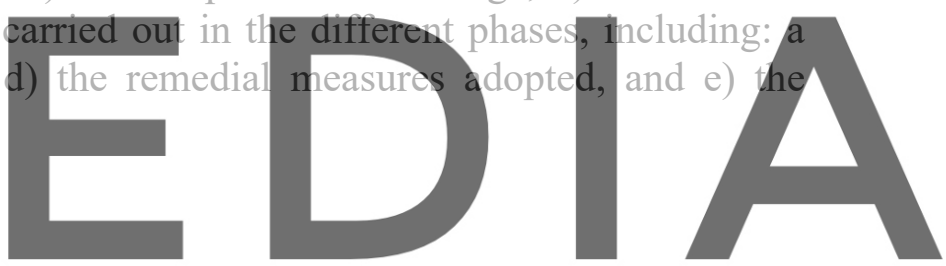

Structurally, the bridge consists of six 22-22-42-42-22-22m spans built with Pratt trusses, and

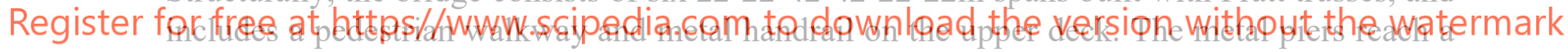
maximum height of $23.6 \mathrm{~m}$ over the foundations. The four lateral spans are isostatic, with two continuous central spans on fixed supports but able to move in the direction of the bridge's axis. The piers consist of steel latticework between four girders that rest on masonry elements. Figure 1 gives the main dimensions and a view of a train passing over the bridge.

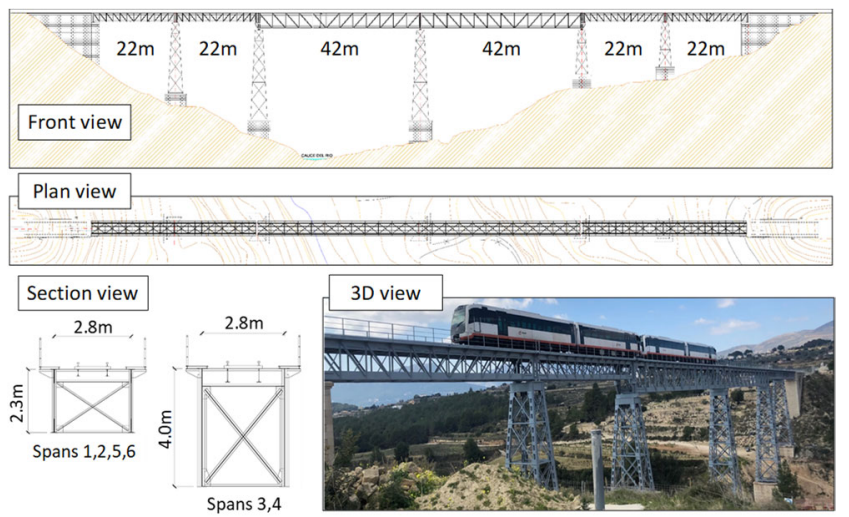

Figure 1: Geometry of the bridge and a general view 
This historically interesting bridge is an example of early $20^{\text {th }}$ century engineering in the province of Alicante. It was built between 1912-15 and is now more than 100 years old and has carried many different types of passenger and goods trains. However, as it was designed in accordance with the standards of the time and was unlikely to meet the present requirements [2], it was given a structural assessment in 2015 which led to its renovation and real time monitoring to ensure it can safely continue to carry trains for another few years. The tasks and studies carried out are described in detail in the following pages, with a special focus on evaluating the bridge's safety as regards its fatigue limits.

\section{METHODOLOGY}

This section describes the method used to assess the Quisi bridge fatigue life and the subsequent proposal of appropriate measures to ensure a safe limit state, for which the Report of the European Convention for Constructional Steelwork (ECCS) and the EC's "Assessment of existing steel structures: Recommendations for Estimation of Remaining Fatigue Life" [4] were followed. This document proposes a method of assessing a structure's fatigue behaviour and its remaining life based on four analytical phases. Advantage was taken of the unique opportunity of using the Ferrandet bridge, which was only a few miles away, with identical spans, built during the same period and carrying the same railway traffic, for this purpose. As this bridge had recently been replaced by a new one, the original structure had been dismantled and was available for testing and so we decided to subject it to a complete set of tests to obtain valid following:
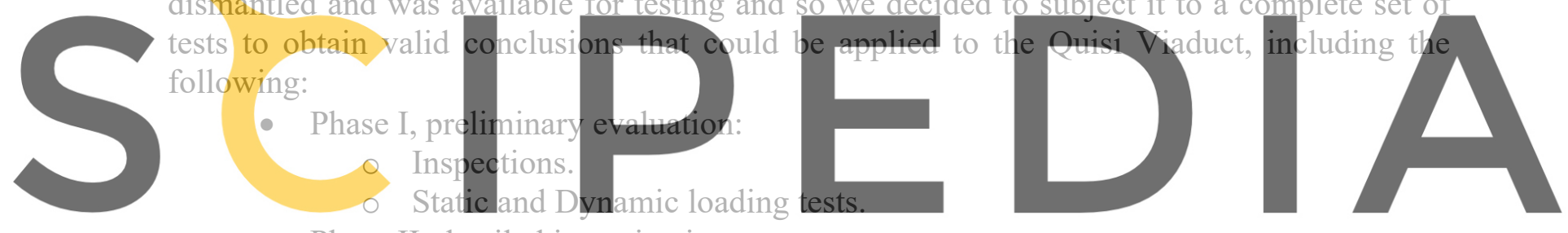

- Phase II, detailed investigation:

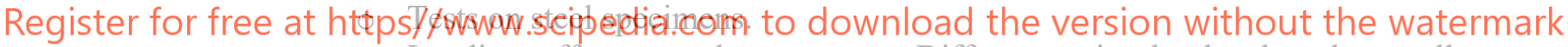
Loading effects on the structure. Differences in the local and overall structural response.

- Definition of the fatigue strength curve. Test until failure on a local element of the structure.

- Test on a full-scale bridge span.

○ Remaining life based on experimental evidence.

- Phase III, in depth analysis:

○ Fracture mechanics. Failure patterns.

- Robustness: Experimental and numerical approach.

- $\quad$ Phase IV, remedial measures.

\section{PRELIMINARY EVALUATION}

The bridge's structural behaviour was analysed in depth by means of: a) a thorough preliminary inspection in accordance with the recommendations in ITPF-05 [3], and b) a loading test to measure strains in the bottom and top chord and deflections at the centre of the 
spans. Shear demand and response of the structure was assessed with strain measurements in diagonal and vertical elements near the supports. The load test considered 4 different load hypotheses (see Figure 2). The dynamic response of the structure was also analysed with trains passing over at $20 \mathrm{~km} / \mathrm{h}$ and $50 \mathrm{~km} / \mathrm{h}$ while monitoring accelerations. The results obtained showed that the bridge was still structurally sound, although the accumulated fatigue in 100 years of service life could compromise its safety and possible produce an accident. The method followed then entered the second step of the study.
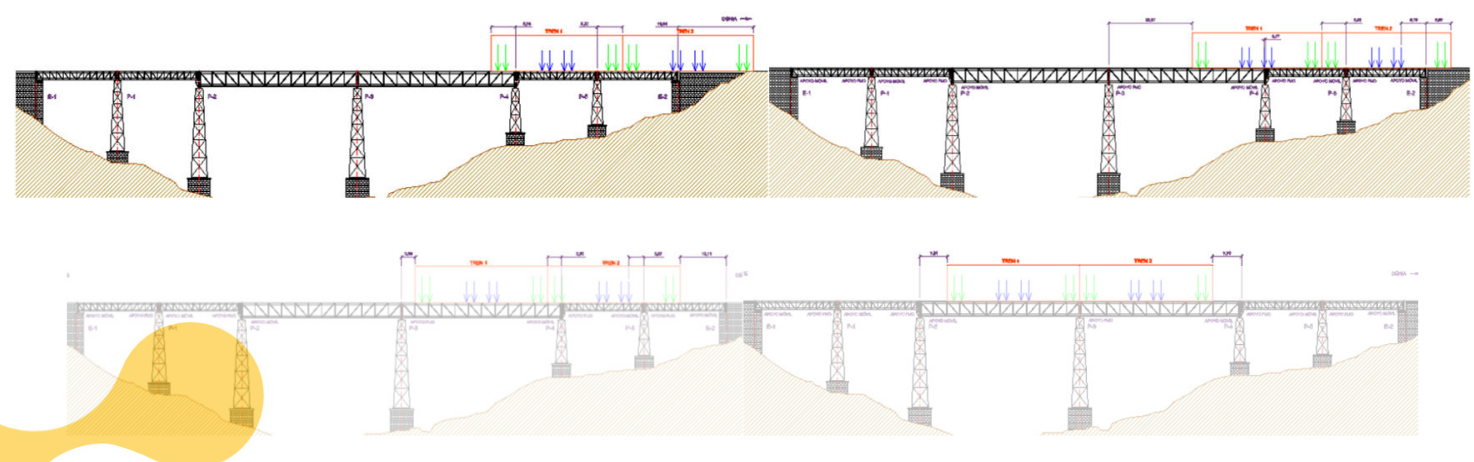

Figure 2: Load hypothesis.

5 DETAILED INVESTIGATION

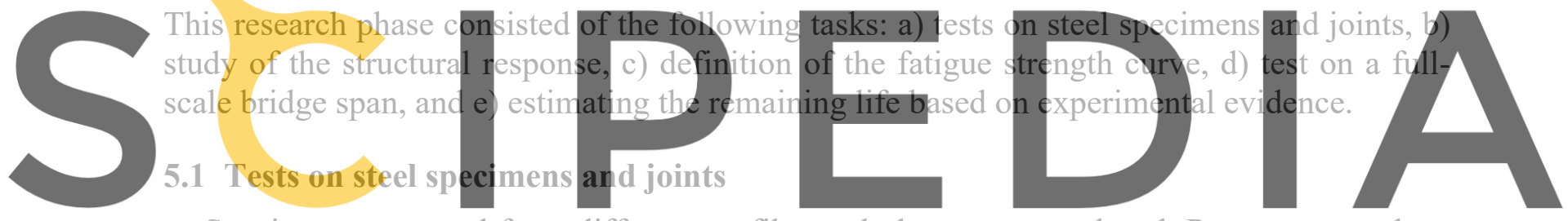

Specimens extracted from different profiles and plates were analysed. Parameters such as

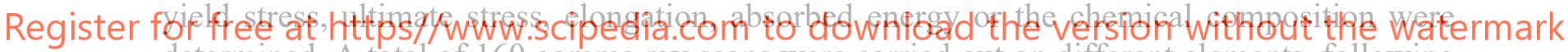
determined. A total of 160 gamma ray scans were carried out on different elements, following EN ISO 5579. Although in general the joints were found to be in good condition, a number of small cracks were found in different components. Figure 3 shows some examples of flaws in scanned rivets.

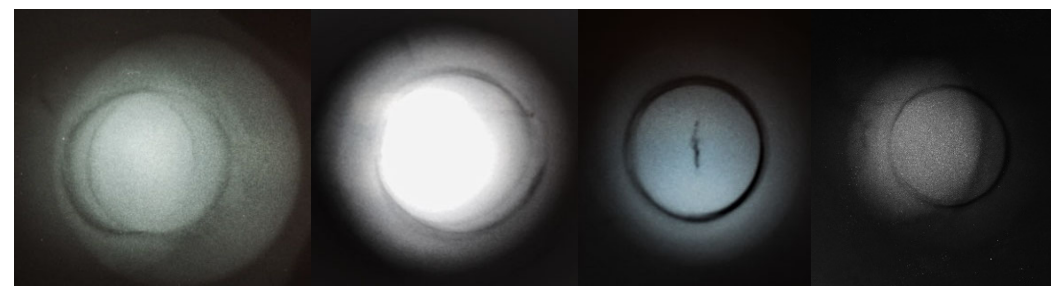

Figure 3. Gamma scans of rivets.

\subsection{Loading effects on the structure. Differences in the local and global structural response}

This section deals with the numerical study on the effects of passing trains on the structure, considering different loading hypotheses and the predominant stresses on different elements. 


\subsubsection{Loads and loading hypotheses considered}

The loads selected were those of the trains that normally passed over the Quisi bridge, a Series 2500 type diesel-powered train with two fully loaded carriages. A sketch can be seen in Figure 4 with the maximum loads on the fully loaded axles.

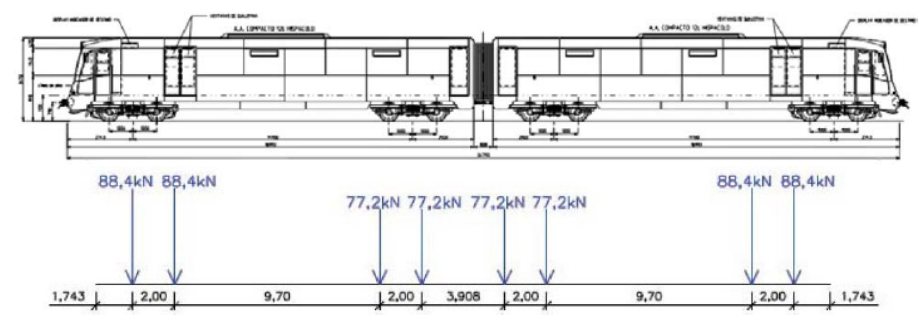

Figure 4. Sketch of train with maximum axle loads.

The maximum stresses on different elements were obtained by a simplified method for the loading hypotheses considered in Section 4 (see Figure 2).

\subsubsection{Results of numerical simulation}

Results were obtained for the geometry of the different bridge elements and a linear-static analysis. For example, Figure 5 gives the axial stress structural response and the vertical displacements of the structure for a specific load hypothesis. As can be extracted from the
structural response and as expected, the bridge behaviour consisted of a series of isostatic and
continuous high-depth beams (trusses) mainly loaded. with axial forces. However, certain
components had a highly local behaviour and transmitted the train loads to the main trusses
by means of a series of elements working with bending stresses. Figure 6 shows the stress
values of one of these-ements with local behaviour working under bending stresses. values of one of these-elements with local behaviour working under bending stresses.

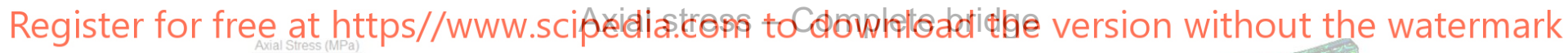

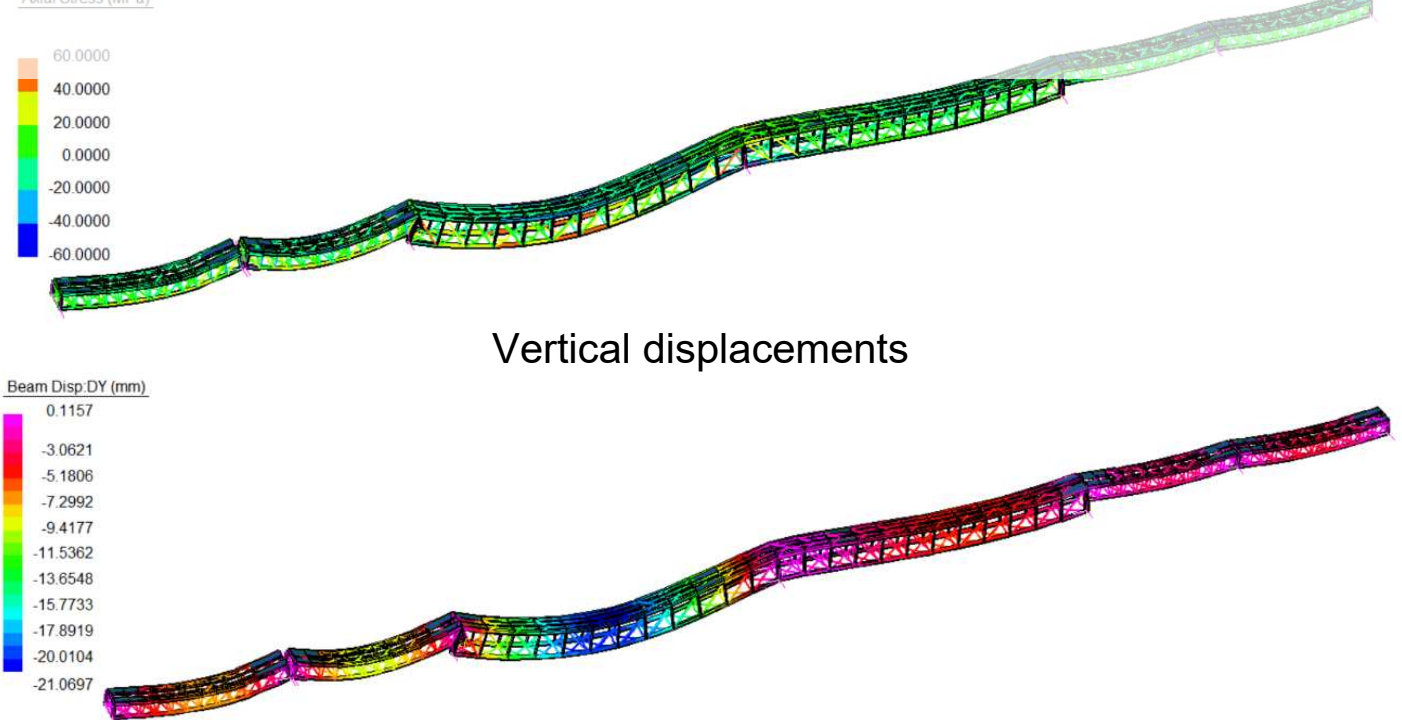

Figure 5. Axial stress and vertical displacements of the structure. 


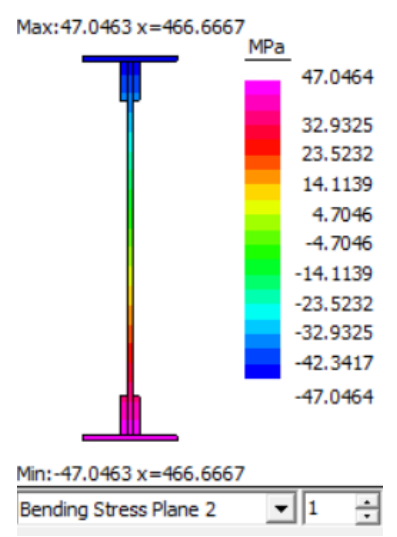

Figure 6. Stresses on an element with local behaviour.

It can be seen that train loads had different effects on the structure: a) a truss behaviour defined as the main general structural response of the structure, and b) a local behaviour of some elements under bending stresses. The study of the bridge's fatigue capacity and remaining service life was thus in two directions to evaluate both its local and general behaviour.

5.3 Definition of the fatigue strength curve. Test until failure on a local element of the structure.

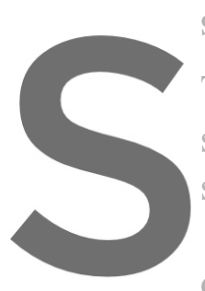

To assess local behavi

subjected to cyclic bending stress incren

stress increments through

This section contains:

of the stresses on the elements to define the fatigue strength curve

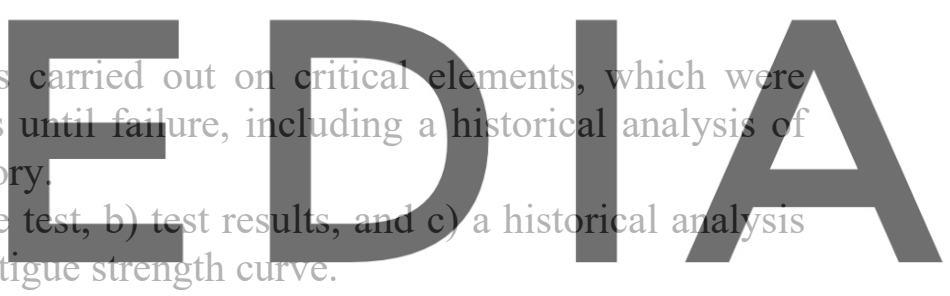

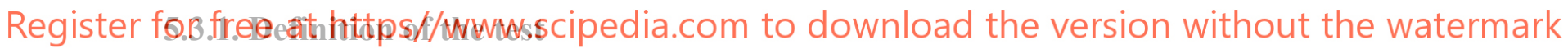

The test was on a lateral joint element with the top chord of the main truss of the bridge as shown in Figure 7, which shows the test setup.
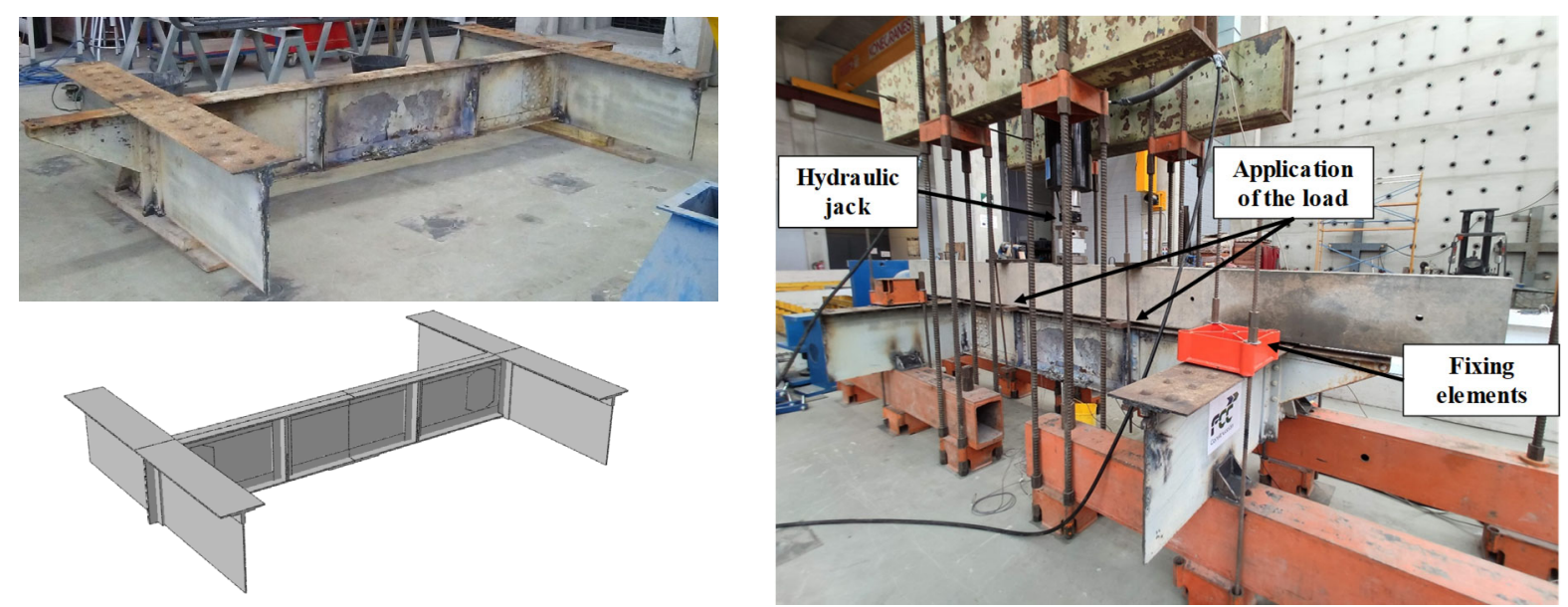

Figure 7. Element selected for testing (left) and test setup (right). 
In these conditions the element was subjected to local loads that reproduced similar bending and shear stresses to those in the bridge. The applied load was defined with the aid of computer models (see also Figure 7). Diverse situations were modelled under different loads. The highest stresses and lowest number of cycles before failure were obtained at the highest load levels. The load increment finally selected was $600 \mathrm{kN}$. The Von Mises stresses in the constant bending moment zone at the centre of the element were expected to reach maximum values of $212.6 \mathrm{MPa}$, at which the number of estimated cycles before failure was 74,472 , adopting a category detail of 71 [4] without considering a previous history of accumulated repetitive loads.

The test was continually monitored by four strain gauges (SG) to measure deformations and two LVDTs to measure deflections and any slippage between the rivets and plates subjected to the highest shear stresses. The positions of the sensors can be seen in Figure 8.
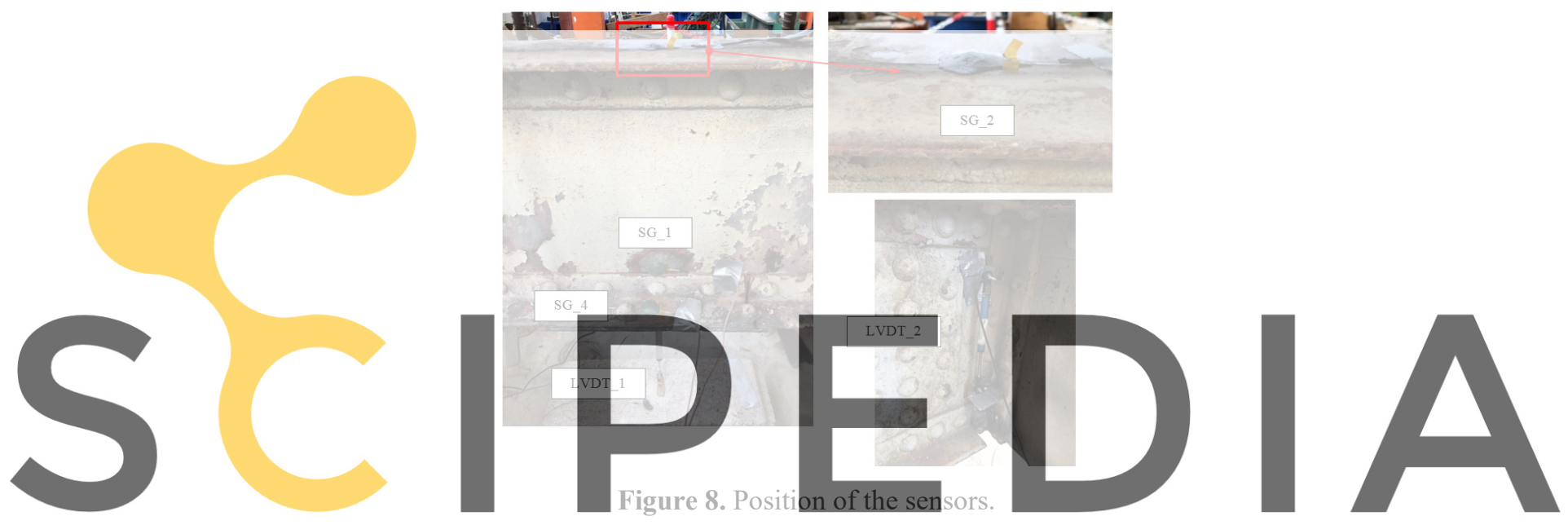

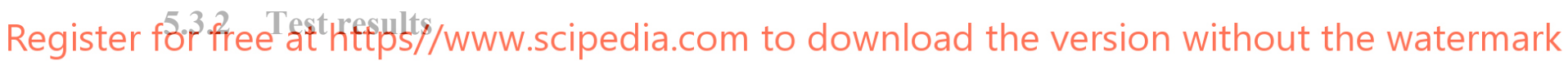
Figure 9 gives an example of the readings from a strain gauge in a short period of time and Figure 10 shows the evolution of the deformation increment measured in each cycle from the start until failure (cycle 31377). The element failed at normal stresses in cycle 31377. Figure 10 shows the fatigue crack that started at the bottom of the element (zone in tension) and propagated to the top of the beam element.

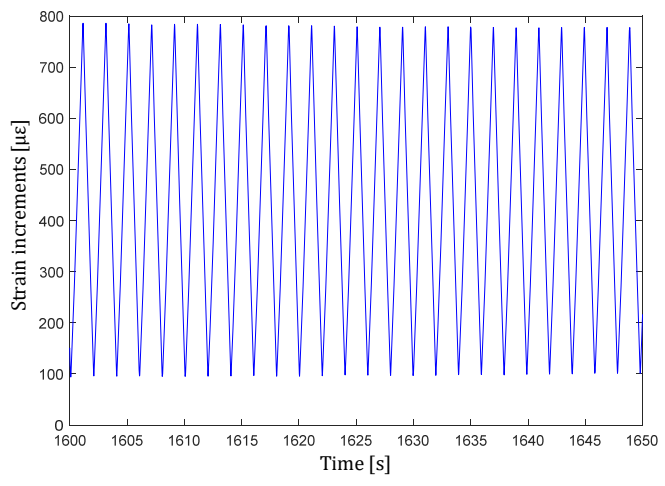

Figure 9. Example of strain measurements. 

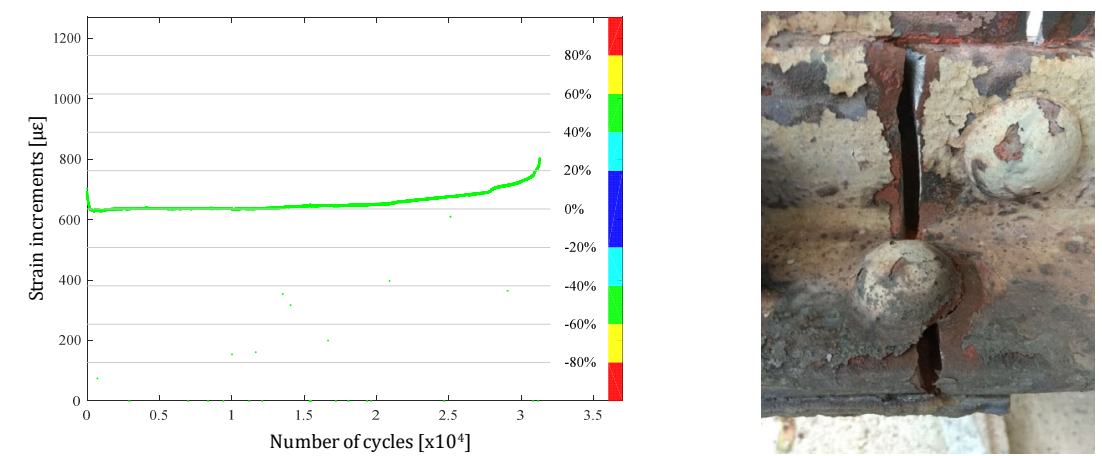

Figure 10. Strain increment evolution of $\mathrm{SG}_{-} 2$ (left) and fatigue crack at the end of the test (right).

\subsubsection{Historical analysis of stresses on the element. Definition of fatigue strength curve}

After the girder had failed it became possible to determine the detail category of this type of element with riveted joints, which belongs to detail category 71 according to EU recommendations [4]. To determine the exact category an analysis of the historical loads was carried out to accompany the test data.

The historical data provided by the railway company on the traffic over the bridge during its lifetime after 1915 showed that 11 different types of train had been used. The only uncertainty in the data was on the weight of the trains since, there was no information available on their load factors and these ranged from completely empty to completely full.

Adopting the damage accunulation method laid down in differe 9 [5] or EAE [6]), the d by considering $100 \%$ to

- Fully loaded trains: detail category Empty trains: detail category 63.
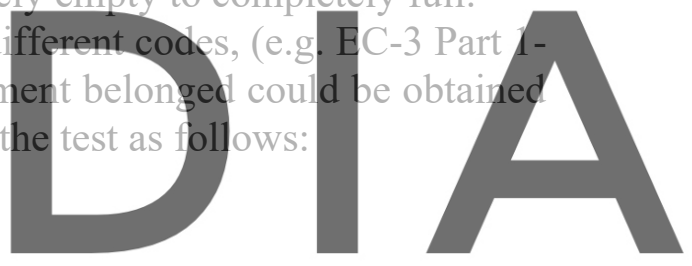

Figure 11 gives a summary of these calculations. It can be seen that the accumulated

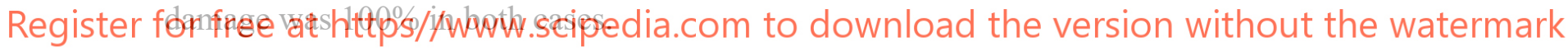
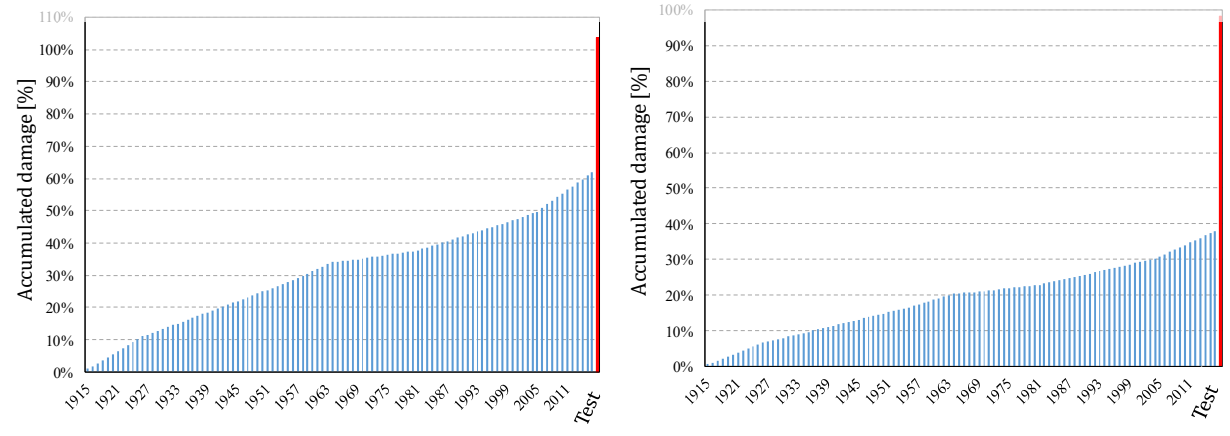

Figure 11. Hypothesis of fully loaded trains (left) and empty trains (right).

\subsection{Test on a full-scale bridge span}

An isostatic span of the Ferrandet bridge was transported from the railway company's premises in Campello (Alicante) to the ICITECH laboratories at the UPV. Photographs of the span during its journey can be seen in Figure12. 


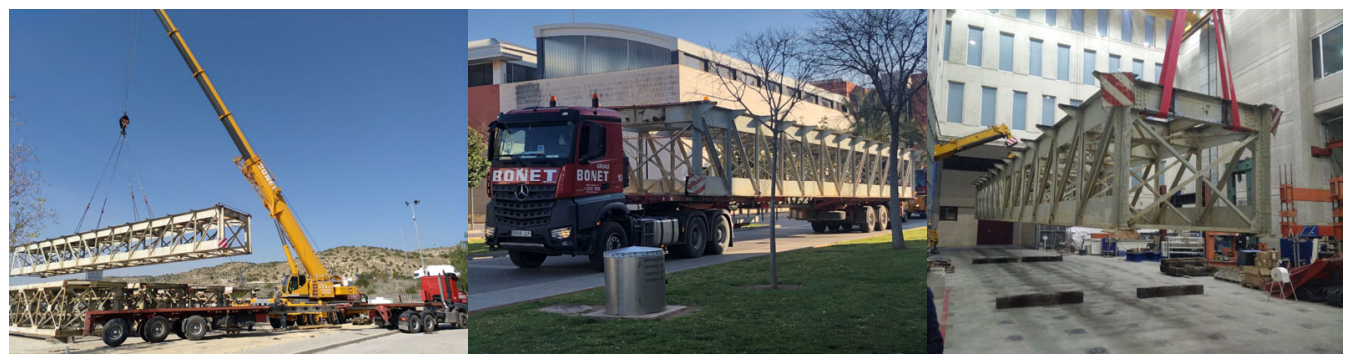

Figure12. Transporting the span from Campello (Alicante) to the UPV (Valencia).

The system used to support the span in its original location was used in the lab tests: hinges that allowed rotation around an axis at each end and metal boxes containing steel ball bearings that allowed longitudinal movement at one end only. Figure 13 shows the supports used in the test setup, while Figure 14 contains a view of the span at the ICITECH laboratories.

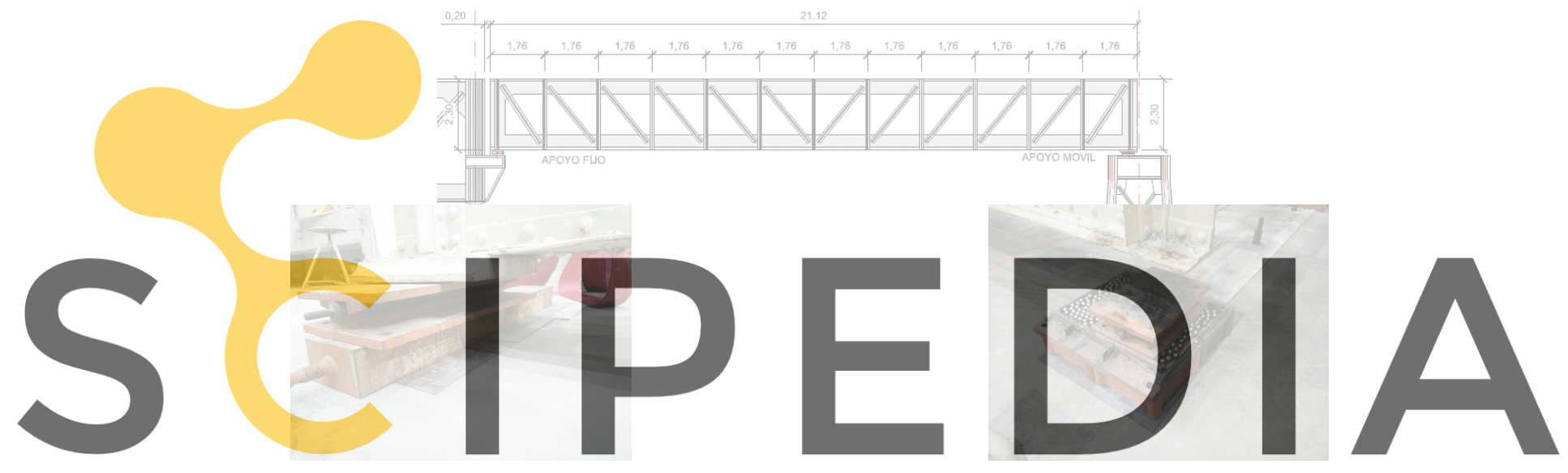

Figure 13. Support system used in the tests.

Register for free at https//www.scipedia.com to download the version without the watermark

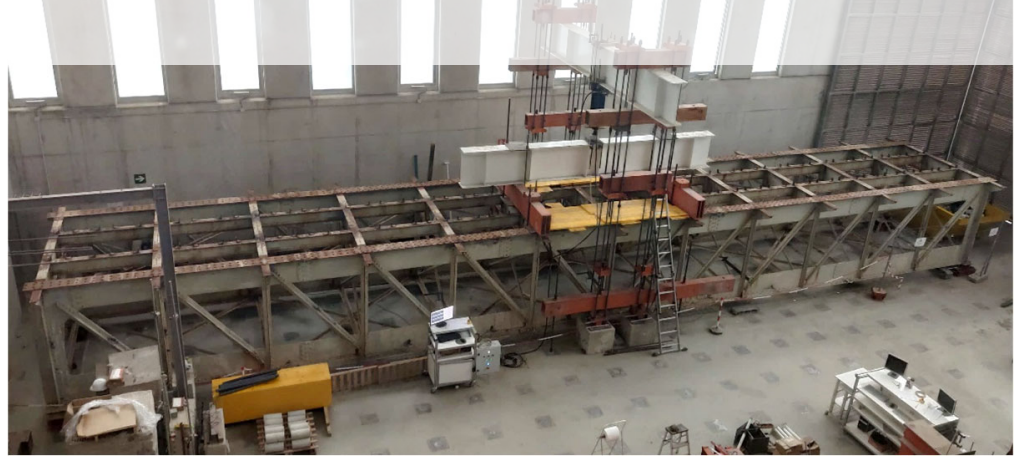

Figure14. General view of the bridge span at the ICITECH laboratories.

\subsubsection{Definition of the test}

The test was defined with the help of computational models with identical geometry and behaviour as the span under study. Figure 15 shows the displacement and stress fields after subjecting the span to a central load of $1250 \mathrm{kN}$. 


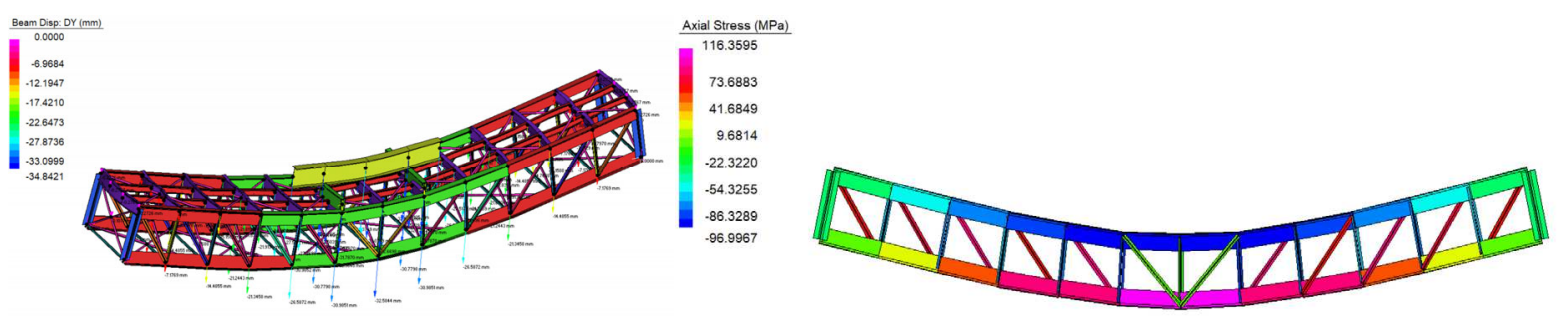

Figure15. Vertical displacements (left) and axial stresses (right) under a load of $1250 \mathrm{kN}$.

LVDTs and strain gauges were used to continually monitor the span during the test, including dynamic tests at the start and finish to determine possible changes of the first mode of vibration due to damage. Figure 16 shows the 40 elements (in red) with strain gauges and the 8 points with displacement sensors. The dynamic tests were performed with accelerometers at the centre of the span and an impact was applied to the centre of the load sharing system.
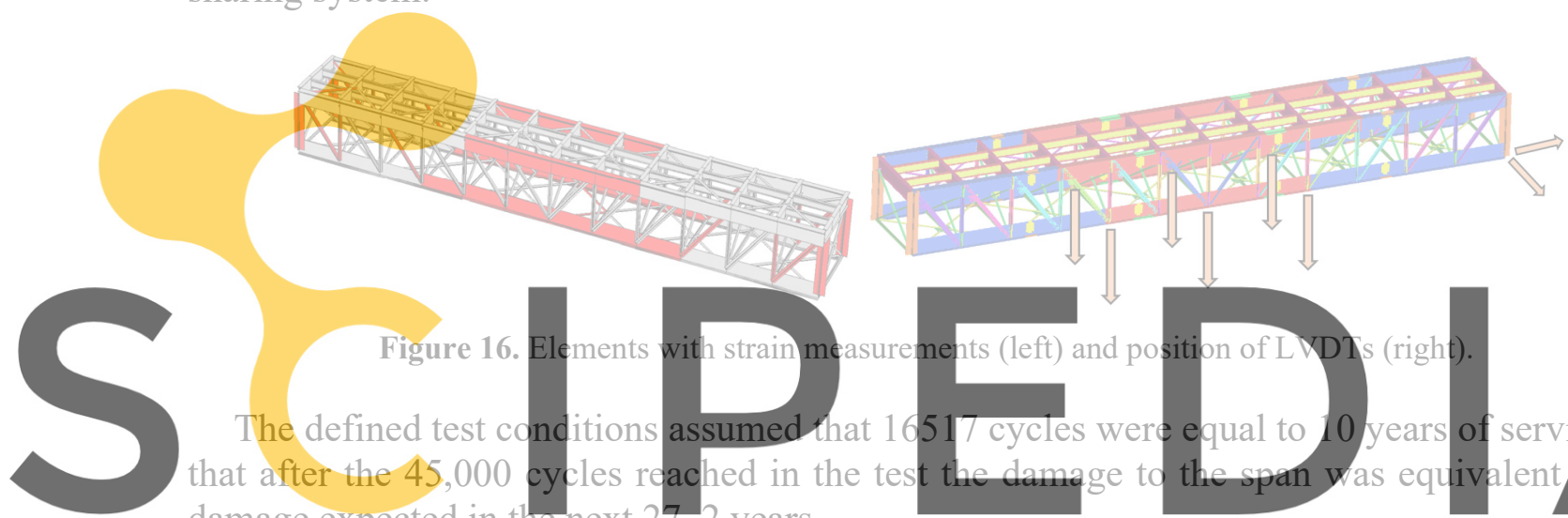
damage expected in the next 27.2 years.
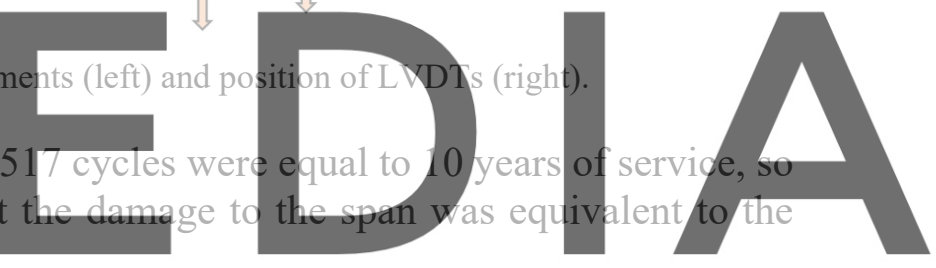

Register fo.4.freelatthttos/s/www.scipedia.com to download the version without the watermark

Figure 17 shows an example of the strain increments in four strain gauges in the last cycle of the test. It can be seen that the structural behaviour at the beginning and end is almost identical.

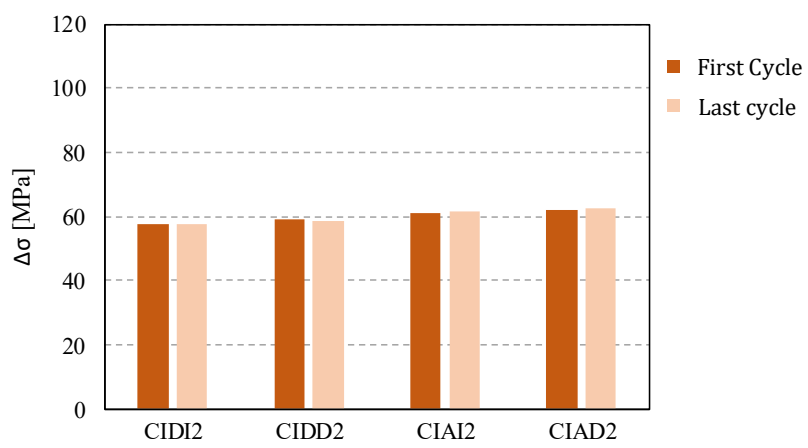

Figure 17. Example of stress increment measurements in 4 strain gauges in the first and last cycle.

The tests revealed clearly elastic linear behaviour with no apparent damage, based on: 
- Stresses clearly lower than the yield stress in the different elements.

- Similar deformation and stress patterns were found in the first and last cycle. Variations were less than $5 \%$ in all cases and below $2.5 \%$ in $85 \%$ of cases.

- Similar deflections and horizontal displacements were found during the entire test and all were below $3 \%$.

The dynamic test gave a variation of $8.40 \mathrm{~Hz}$ at the start and $8.05 \mathrm{~Hz}$ in the first mode of vibration in the structure at the end of the cycle, which implies a frequency reduction of $4.2 \%$ and shows a slight increase in the bridge flexibility. Together with the variations obtained by the deformation and displacement sensors, this value shows the minimum variation in the general bridge behaviour after the intense fatigue test it had been subjected to. There were no signs of failure or weakness in any of the elements.

\subsection{Remaining life based on experimental evidence}

The tests showed that the most critical elements were those in the load sharing structure (see Section 5.3), which reached fatigue failure in the test. The damage accumulation method was used to estimate these elements' remaining useful life, which was around 10.7 years. The remainder of the elements of the main structure (trusses) had a longer remaining life and did not reach failure with damage equivalent to 27.2 years of service.

\section{IN-DEPTH ANALYSIS}

Apart from the lab tests, other deeper tests were carried out by means of fracture mechanics techniques and the bridge's structural robustness was tested against possible local failures in some elements.

\subsection{Fracture mechanics. Failure patterns}

Computational simulations and analytical studies were used to evaluate and reinforce the conclusions reached up to this point. The analytical studies were by means of fracture mechanics and confirmed that the fracture of the elements in the local load sharing system would occur at the same or even slightly higher number of cycles than in the experimental tests and those calculated by applying the expressions in EC-3[5]. This confirmed that the bridge would have a remaining service life of 10.7 years, the same as that calculated from the experimental tests.

Similar results were also obtained from the computational models. For example, the numerical prediction found that cracks would begin to appear after 7530 cycles (experimentally, between 10,000 and 15,000) with similar propagation patterns to those obtained experimentally (see Figure 18).

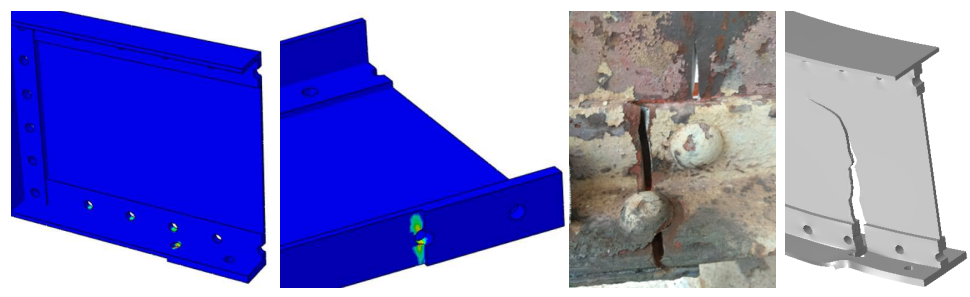

Figure 18. Computational models for triggering cracks (left) and predicting the cracking pattern (right). 


\subsection{Robustness: Experimental and numerical approach}

Robustness against possible failure of elements in the bridge's main latticework was also studied by recreating artificially failures in the main trusses. The aim was thus, not to determine the causes of possible crack initiation and propagation, but to determine the consequences of a local element failure, known as the scenario-independent approach [7-10], widely used to study progressive or disproportionate structural collapse after a local failure. This method can evaluate structural robustness understood as insensitivity to or propagation of a local failure.

The study was in two parts: experimental and numerical (see Figure 19). In the first, two of the most critical diagonals were cut at different damage levels, while the second simulated the failure of a critical element under tensile loads. Both methods were aimed at studying the alternative load paths and robustness of the structure.

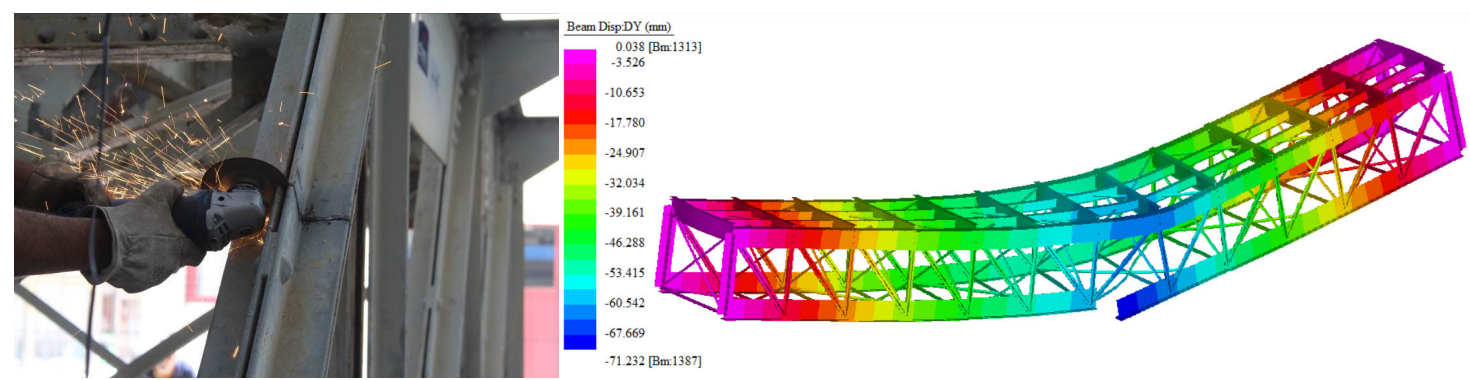

Figure 19. Experimental (left) and numerical (right) study of the influence of different levels of damage on the behaviour of the structure.

The results showed that the structure, normally considered as an isostatic structure working solely under axial stresses, had a certain redundancy and was able to withstand this type of failure, activating for this purpose some of the alternative load paths with high bending stresses at the joints.

\section{REMEDIAL MEASURES}

The bridge under study was planned to continue in service for three additional years. After the study it was decided to keep it in operation with a series of remedial measures.

- Real time monitoring, considering the crucial elements that could trigger a failure of the structure and develop a fatigue crack.

- Periodical inspections.

- Limitation to a lighter type of train than others.

- Limited number of trains per day.

\section{CONCLUSIONS}

This paper describes the evaluation of the fatigue limit state of the Quisi Viaduct in Alicante (Spain) carried out by the Calsens Company, a spin-off of the Universitat Politècnica de València, in collaboration with the ICITECH. The study included all the stages recommended by [4], from a preliminary assessment to an in-depth analysis and took advantage of the unique opportunity of having an identical bridge available for the study, 
including ambitious experimental tests and subjecting an entire bridge span to fatigue tests at the ICITECH laboratories.

The results obtained showed that the Quisi Viaduct has a local load sharing system with a high amount of accumulated damage. However, the structure's overall behaviour presents a greater margin of safety and redundancy. Apart from the fact that the bridge will be out of service in three years, the tests carried out led to a series of strict remedial measures to ensure it can safely remain in service for this time.

\section{ACKOWLEDGEMENTS}

The authors wish to acknowledge their gratitude to the companies that confided this work to Calsens: FCC, CHM and CONVENSA, and special thanks to FGV and Juan Antonio García Cerezo for all the facilities they gave us to successfully carry out the tests.

\section{REFERENCES}

[1] Pipinato A, Pellegrino C, Bursi OS, Modena C. High-cycle fatigue behavior of riveted connections for railway metal bridges. J Constr Steel Res 2009;65:2167-75. doi:10.1016/j.jcsr.2009.06.019.

[2] Ministerio de Fomento. Instrucción de acciones a considerar en puentes de ferrocarril (IAPF) 2010:134.

[3] Ministerio de Fomento. Instrucción sobre las inspecciones técnicas en los puentes de ferrocarril (ITPF-05) 2005:8.

[4] Kühn B, Lukic M, Nussbaumer A, Günther HP, Helmerich R, Herion S, et al. Assessment of existing steel structures: Recommendations for estimation of the remaining fatigue life. vol. EUR 23252. Luxembourg: 2008. doi:10.1016/j.proeng.2013.12.057.

[5] EN 1993-1-9. Eurocode 3: Design of steel structures. Part 1-9: Fatigue 2009.

[6] EAE. Instrucción de Acero Estructural 2011.

[7] Lin S-C, Yang B, Kang S-B, Xu S-Q. A new method for progressive collapse analysis of steel frames. J Constr Steel Res 2019;153:71-84. doi:10.1016/j.jcsr.2018.09.029.

[8] Buitrago M, Sagaseta J, Adam JM. Effects of sudden failure of shoring elements in concrete building structures under construction. Eng Struct 2018;172:508-22. doi:10.1016/j.engstruct.2018.06.052.

[9] Adam JM, Buitrago M, Bertolesi E, Sagaseta J, Moragues JJ. Dynamic performance of a real-scale reinforced concrete building test under corner-column failure scenario. Eng Struct 2020.

[10] Buitrago M, Sagaseta J, Adam JM. Avoiding failures during building construction using structural fuses as load limiters on temporary shoring structures. Eng Struct 2020;204:1-16. 